\title{
Isolated Open Rotor Noise Prediction Assessment Using the F31A31 Historical Blade Set
}

\author{
Douglas M. Nark, William T. Jones $\rceil^{\dagger}$ D. Douglas Boyd, Jr. $\ddagger$ and Nikolas S. Zawodny ${ }^{\S}$ \\ NASA Langley Research Center, Hampton, VA 23681-2199
}

In an effort to mitigate next-generation fuel efficiency and environmental impact concerns for aviation, open rotor propulsion systems have received renewed interest. However, maintaining the high propulsive efficiency while simultaneously meeting noise goals has been one of the challenges in making open rotor propulsion a viable option. Improvements in prediction tools and design methodologies have opened the design space for next generation open rotor designs that satisfy these challenging objectives. As such, validation of aerodynamic and acoustic prediction tools has been an important aspect of open rotor research efforts. This paper describes validation efforts of a combined computational fluid dynamics and Ffowcs Williams and Hawkings equation methodology for open rotor aeroacoustic modeling. Performance and acoustic predictions were made for a benchmark open rotor blade set and compared with measurements over a range of rotor speeds and observer angles. Overall, the results indicate that the computational approach is acceptable for assessing low-noise open rotor designs. Additionally, this approach may be used to provide realistic incident source fields for acoustic shielding/scattering studies on various aircraft configurations.

\section{Introduction}

In an effort to mitigate next-generation fuel efficiency and environmental impact concerns for aviation, alternatives to today's commonly-used turbofan propulsion systems have received renewed interest. Open rotors are one option that have the potential to significantly reduce fuel burn relative to conventional turbofan engines. This advantage was demonstrated as part of a comprehensive study of open rotors in the 1980s by NASA and the U.S. aircraft engine industry $\frac{1.22}{10}$ Hower, maintaining the high propulsive efficiency while simultaneously meeting noise goals has been one of the challenges in making open rotor propulsion a viable option.

Improvements in prediction tools and design methodologies have opened the design space for next generation open rotor designs that satisfy these challenging objectives. As such, NASA and General Electric Aviation recently embarked on a joint effort to investigate modern blade designs. Validation of aerodynamic and acoustic prediction tools was an important aspect of the effort and a baseline blade set representative of early 1990s designs was included in testing. This paper describes a combined computational fluid dynamics (CFD) and Ffowcs Williams and Hawkings (FW-H) equation methodology for open rotor aeroacoustic modeling. Specifically, two separate (one structured and one unstructured) CFD codes were used to predict the aerodynamic performance of the baseline F31A31 blade set. Resultant blade surface pressure from the aerodynamic predictions were then used as input to two separate $\mathrm{FW}-\mathrm{H}$ solvers to predict the open rotor noise source. Predicted and measured performance and acoustic results were then compared over a range of rotor speeds and observer angles (at a single Mach number and zero angle of attack).

The remainder of the paper details the aerodynamic and acoustic predictions, as well as the resultant comparison with measured data. The selected test configuration and operating conditions of interest are first presented in Section II This is followed by a discussion of the aerodynamic calculations in Section III. Generation of the acoustic predictions and comparison with measurements are then presented in Section IV Finally, concluding remarks regarding some of the more significant results and further areas of interest are presented in Section $\mathrm{V}$

\footnotetext{
* Senior Research Scientist, Research Directorate, Structural Acoustics Branch, AIAA Associate Fellow

$\dagger$ Senior Research Scientist, Research Directorate, Computational Aerosciences Branch, AIAA Associate Fellow

${ }^{\ddagger}$ Senior Research Engineer, Research Directorate, Aeroacoustics Branch, AIAA Senior Member

${ }^{\S}$ Research Aerospace Engineer, Research Directorate, Aeroacoustics Branch, AIAA Member
} 


\section{Test Configuration}

A blade design called the historical blade set (also known as F31/A31) was chosen to serve as the baseline for this validation study. This selection was due in large part to the wealth of geometric, aerodynamic, and acoustic data sets available. A sub-scale model of this blade set having 12 front rotor blades and 10 aft rotor blades with a diameter of approximately 25.6 inches $(0.65 \mathrm{~m})$ was tested in NASA wind tunnels $\left.{ }^{3}-5\right]$ This included low speed testing in the NASA 9-ft. x 15-ft. (2.7m x 4.6m) wind tunnel to investigate aerodynamic and acoustic performance, as well as high speed testing in the NASA 8 -ft. x 6-ft. $(2.4 \mathrm{~m} \times 1.8 \mathrm{~m})$ wind tunnel. This work focuses on the isolated, zero angle of attack low speed configuration as tested in the NASA 9-ft. x 15-ft. wind tunnel (see Figure 1). During this testing, acoustic data was acquired at 18 microphone positions along a linear traverse offset $5 \mathrm{ft}$. $(1.52 \mathrm{~m})$ from the centerline of the model. The measurements cover geometric observer angles between $17.6^{\circ}$ (upstream) and $140^{\circ}$ (downstream) from the open rotor axis (see Figure 1 and Table 1 .

This study focuses on comparison between the predicted and measured tonal components since these dominate the acoustic spectra for this blade set. In order to make a direct comparison between the tonal acoustic amplitudes of the experimental and computational data sets, an extraction technique was performed on the experimental narrowband acoustic spectra. Following approaches employed by Envia ${ }^{6}$ and Rizzi et al.,,$^{7}$ a peak-finding algorithm was implemented to identify tones in the acoustic narrowband spectra, using a threshold value of $2 \mathrm{~dB}$. Specifically, the spectral value at a frequency bin was flagged as a "tone" if it was at least $2 \mathrm{~dB}$ above one of its neighboring bins. To account for the effects of spectral leakage, the total energy of the flagged "tone" was estimated as the sum of the energy in the frequency bins spanning two frequency bins on either side of the flagged frequency bin.

\section{Aerodynamic Predictions}

Both structured (OVERFLOW 2) and unstructured (FUN3D) computational fluid dynamics (CFD) codes are used in this study to predict open rotor aerodynamic performance and obtain blade loading information.

\section{A. OVERFLOW 2}

OVERFLOW $2^{8-11}$ is a three-dimensional time-marching implicit Navier-Stokes code that uses structured overset grid systems. Several different inviscid flux algorithms and implicit solution algorithms are included and the code has options for thin layer or full viscous terms. A wide variety of boundary conditions are available, as well as algebraic, one-equation, and two-equation turbulence models. Low speed preconditioning is also available for several of the inviscid flux algorithms and solution algorithms in the code. The code also supports bodies in relative motion, and includes both a six-degree-of-freedom (6- DOF) model and a grid assembly code.

In the current study, OVERFLOW 2 simulations were performed using a dual time-stepping scheme. The optimized second order backward differencing formulation (BDF2OPT) was utilized with a fixed number of 60 Newtonian sub-iterations per physical time-step. As a result of this fixed number of sub-iterations, the $L_{\infty}-$ norm (RHS) orders of convergence varied between 4 and 7 depending on the simulation case. A local CFL number was determined by using the sum of maximum eigenvalue in each coordinate direction, with an upper limit CFL number $\left(\mathrm{CFL}_{\max }\right)$ of 5. Spatial differencing was carried out using a fourth order central differencing scheme for inviscid terms, and a second order central differencing scheme for the viscous terms. The one-equation turbulence model of Spalart and Allmaras along with a Detached Eddy Simulation (DES) and the rotation/curvature correction (SARC) was utilized.

Overset grid generation was performed using the Chimera Grid Tools v2.1 software package $\frac{12 \mid 13}{13}$ and the open rotor computational grid consists of ten levels, one overset near-body grid level (per surface component) and nine Cartesian off-body grid levels, totaling approximately 160 million grid points. The overset near-body grids make up approximately $41 \%$ of the total number of grid points. Furthermore, the near-body grids extend outward from the rotor blades approximately $30 \%$ of the mean blade chord (based on the F31 blade), and outward from the rotor center body approximately 1.2 mean blade chords. The first level Cartesian off-body grid has a uniform spacing of approximately $4 \%$ of the mean blade chord. The remaining Cartesian off-body grids were generated automatically by OVERFLOW 2 and extend approximately 30 rotor tip radii outward in all directions.

The aerodynamic simulations utilized 600 computer cores on the NAS Pleiades supercomputer for all cases. A converged solution was found to be conservatively obtained in five full rotor revolutions using the time-stepping scheme discussed above, regardless of the physical time step used. Each physical time step in the solution required approximately 60 seconds (one second per sub-iteration) using the BDF2OPT scheme. This resulted in a total simulation time of 24 hours per revolution using a $0.25^{\circ}$ azimuthal resolution, and six hours per revolution using a $1.0^{\circ}$ azimuthal 
resolution.

\section{B. FUN3D}

The FUN3D flow solver ${ }^{14}$ has an extensive set of options and solution mechanisms for spatial and temporal discretizations on general static or dynamic mixed-element unstructured meshes that may or may not contain overset mesh topologies. In the current study, the spatial discretization uses a finite-volume approach in which the dependent variables are stored at the vertices of mixed element meshes. Inviscid fluxes at cell interfaces are computed by using the upwind scheme of Roe, ${ }^{19}$ and viscous fluxes are formed by using an approach that is equivalent to a central difference Galerkin procedure. The eddy viscosity is modeled by using the one-equation approach of Spalart and Allmaras 20 with the source term modification proposed by Dacles-Mariani et al.21 Scalable parallelization is achieved through domain decomposition and message-passing communication.

An approximate solution of the linear system of equations that is formed within each time step is obtained through several iterations of a multicolor Gauss-Seidel point-iterative scheme. The turbulence model is integrated all the way to the wall without the use of wall functions. The turbulence model is solved separately from the mean flow equations at each time step with a time integration and a linear system solution scheme that is identical to that employed for the mean flow equations.

A dual time-stepping algorithm with sub-iterations is used to converge the solution within each physical timestep. For these simulations, a maximum of 20 sub-iterations per time-step was used. However, a temporal error controller was used to monitor the sub-iteration convergence history advancing to the next physical time-step when the flow residuals dropped below ten percent of the estimated temporal error. A variety of time marching schemes are available in FUN3D, including a second-order backward-differencing formulation (BDF2), and an optimized second order backward differencing formulation (BDF2OPT). The BDF2OPT scheme ${ }^{22}$ was chosen for the current application as it produces lower truncation error compared to the standard BDF2 scheme at nominally the same computational cost but with slightly increased memory usage.

The generation of the individual components used to define the overset mesh system were performed with the GridEx meshing framework. ${ }^{23}$ Surface meshes were generated directly on the Computer Aided Design (CAD) geometry through the CAPRI interface ${ }^{24}$ and leveraging the VGRID algorithm. ${ }^{25}$ The volume meshes were generated via the Advancing Front with Local Reconnection in 3D (AFLR3) software ${ }^{26}$ The complete unstructured composite mesh consisted of approximately 103 million mesh vertices with $30 \%$ representing the mesh in the immediate vicinity of the fore and aft blade rows. The maximum mesh spacing on all solid surfaces was limited to $2 \%$ of the mean blade chord. The geometry model included the sting aft of the nacelle centerbody, but did not consider the blade attachment to the tunnel floor. Thus, the computational domain was defined by a cylinder about the centerbody centerline with a radius of 40 times the radius of the forward blade row, extending $80 \mathrm{~F} 31$ mean blade chords upstream of the nacelle and 160 chords downstream of the sting.

The overset mesh system was assembled with SUGGAR ++27 establishing domain connectivity information for the components. Due to the periodic motion of the geometry and the assumption of rigid blades, the domain connectivity information for the component positions at each time step was pre-computed as a pre-processing step to flow simulation. The domain connectivity information was then loaded from disk at each time-step of the simulation thereby increasing the efficiency of the simulation.

The aerodynamic simulations utilized 2048 computer cores on the NAS Pleiades supercomputer for all cases and were run fully dense on Intel Sandybridge processors. A periodic solution was conservatively considered to be obtained after six full rotor revolutions using the time-stepping scheme discussed above. FW-H data was extracted on a seventh revolution. A physical time step in the solution required approximately 50 seconds on average using the BDF2OPT scheme with a variable number of sub-iterations determined by the temporal error controller. This resulted in a simulation time of five hours per revolution using a $1.0^{\circ}$ azimuthal resolution.

\section{Aerodynamic Results}

Three rotor speeds, shown in Table 2 were considered ranging from the approach RPM to the nominal takeoff RPM. As also presented in Table 2, the front and aft rotors were operated at the same RPM and with identical blade setting angles. The tunnel Mach number (i.e., open rotor "forward flight speed") was held fixed at 0.2. Rigid blade shapes corresponding to those at the maximum climb condition were also used at all tip speeds. Therefore, any small change in "hot" blade shape as a function of RPM were not included. Initial aerodynamic predictions for both codes utilized a time resolution equivalent to an azimuthal angle of $1.0^{\circ}$. However, decisions related to grid generation led to different treatments of the aft portion of the nacelle centerbody as shown in Figure 3 . In the OVERFLOW2 predictions, the 
choice was made to truncate and round the aft portion of the centerbody to minimize downstream boundary influences. In contrast, the FUN3D predictions included the full extent of the downstream portion of the centerbody. As indicated in subsequent discussion on the acoustic prediction (Section IV], this does not affect the geometry of the acoustic data surfaces. In addition, because only isolated rotors are considered, any effects on scattering/shielding surfaces are not included. However, it should be noted that this difference in aft centerbody may effect the predicted loading values on the acoustic data surfaces.

Comparison of predicted and measured total thrust and torque ratio, presented in Figure 4 , show the two codes to provide consistent performance predictions. Good agreement is achieved for total thrust with a slight discrepancy at the highest RPM. However, less favorable comparison is achieved for the torque ratio, particularly at lower RPM. This may perhaps be expected, as the blade angles settings digress from design point as the RPM is reduced. This might therefore lead to increased flow separation requiring enhanced grid resolution to properly capture. In light of this and standard practice, a temporal and spatial grid refinement study is in order. Such a full study is not included in this work, however, an initial OVERFLOW 2 temporal resolution study was undertaken. As such, additional aerodynamic predictions were performed using temporal resolutions corresponding to azimuthal angles of $0.5^{\circ}$ and $0.25^{\circ}$. The resultant performance parameter predictions are presented in Table 3 A clear trend is difficult to discern, indicating the need for a fuller (temporal and spatial) grid refinement study. However, based on the reasonable comparison of performance metrics, the available loading values were used in subsequent acoustic calculations.

\section{Acoustic Predictions}

The acoustic prediction methods used in this study are based on the FW-H equation, $\frac{28}{2}$ which is a rearrangement of the exact continuity and Navier-Stokes equations into a wave equation for the density with a nonlinear forcing term. Through the application of generalized functions and a Green's function technique, the solution to the equation can be reduced to a surface and a volume integral. However, the solution is often well approximated by the surface integral alone, as the volume integral includes physical effects such as refraction and nonlinear steepening. When these effects are small, the FW-H surface can coincide with the solid body generating the unsteady flow. This is often referred to as an impermeable data surface. When effects such as refraction are important, the FW-H surface can be pushed out into the flow to encompass important flow gradients. In this case, the data surface is referred to as being permeable (also, penetrable or porous). Hence, the time history of the density, which is directly related to the pressure in the far-field, can be obtained at locations far from the body from a surface integral that is either close to or on the actual body. For permeable surfaces that are off the body, the time histories of all the flow variables are needed, but no spatial derivatives are explicitly required. For surfaces coinciding with the body, only the pressure time history is needed.

The PSU-WOPWOP (PSW) $\operatorname{code}^{29}$ and the F1A module of NASA's second generation Aircraft NOise Prediction Program (ANOPP2),$\sqrt[30]{6}$ both implementing Farassat's retarded-time formulation 1A of the FW-H equation, were used as part of the acoustic prediction process. In particular, both the PSW and ANOPP2 solvers were used for the acoustic predictions based on the structured code (i.e., OVERFLOW 2) loading and the two codes provided nearly identical results. Therefore, only a single set of results based on the OVERFLOW 2 loading are presented and may be considered indicative of both acoustic prediction codes. Conversely, comparisons of the acoustic predictions for the unstructured (i.e., FUN3D) loading are ongoing and only those using the PSW code are presented herein.

All acoustic predictions were based on impermeable data surfaces. As seen in Figure 5 , only the rotor blade surfaces were included for which the required surface pressure values were provided by the aforementioned CFD solvers. In addition to the rotor surfaces, the OVERFLOW 2 data surfaces contained a portion of the collar grids for each blade. This was necessary to account for the blade root and the inclusion of the small portion of nacelle surface had a negligible effect on the acoustic results. In specifying the geometry and loading values for the acoustic data surfaces, the information may be considered 'constant', 'periodic', or 'aperiodic'. Information specified as 'constant' is assumed to remain unchanged for all source times. In terms of geometry, this means that the blade shapes remain unchanged as they rotate. For loading specification, the surface pressure values would remain unchanged as the blades rotate (as would be the case if the mean loading values were specified). For 'periodic' data, values are taken to change as a function of azimuthal angle. Finally, for 'aperiodic' data, values are taken to change arbitrarily as a function of time. As mentioned previously, the blades were assumed rigid, with shapes taken to be the same at all speeds. Therefore, within the acoustic calculations, the geometry of the acoustic data surfaces could be considered 'constant' and rotating at the specified RPM. This meant that surface geometry for only a single CFD time step would be needed as input. Alternatively, the data surfaces could be specified as 'periodic' and the geometry for all time steps would be needed. Predictions were performed using both approaches to verify input specification and, as expected, essentially identical results were obtained. Therefore, the acoustic data surface geometry was specified as 'constant' in 
subsequent predictions due to the reduction in input file size. Conversely, the surface pressure loading was taken to be 'periodic' (i.e., changing as a function of azimuthal angle and repeating on a once-per-revolution basis). Specifically, time dependent surface pressure loading values for one full rotor revolution were extracted from the CFD solutions (after suitable convergence was reached) and used as input. Initially, baseline acoustic predictions were performed using CFD values at $1.0^{\circ}$ azimuthal resolution. Additional predictions were then performed using higher temporal resolution CFD results.

\section{A. Baseline Results}

Acoustic predictions were obtained at observer locations corresponding to the 9'x15' wind tunnel microphone arrangement shown in Figure 2. While the separate thickness (monopole) and loading (dipole) acoustic contributions are obtained in the predictions, only the total values are presented for comparison with measured values. In an attempt to cover a range of possible metrics for prediction assessment, comparisons include the directivity for a number of dominant tones, tonal amplitudes for a subset of shaft orders, and overall sound pressure levels. Figure 6 shows the predicted and measured tone sound pressure level (SPL) as a function of sideline angle at the highest tip speed (6436 $\mathrm{RPM})$ for a number of notable tones of interest. Comparisons begin with the blade passage frequency of the aft $\left(\mathrm{BPF}_{2}\right)$ and forward $\left(\mathrm{BPF}_{1}\right)$ blade rows and continues through various interaction tones (additive combinations of $\mathrm{BPF}_{1}$ and $\mathrm{BPF}_{2}$ ). Included in the captions are the corresponding multiples of the open rotor shaft frequency (i.e., shaft order). For this case, the shaft frequency is $107.3 \mathrm{~Hz}$ and $\mathrm{BPF}_{2}$, for example, corresponds to a shaft order of 10 . As can be seen, the individual rotor tones corresponding to shaft order 10 and 12 are captured quite well, particularly around the broadside angles. Results for the first interaction tone, $\mathrm{BPF}_{1}+\mathrm{BPF}_{2}$, are less favorable. However, the trends in the data appear to be reasonably well predicted over the range of interaction tones considered. In an effort to investigate this further, comparison of measured and predicted SPL for shaft orders up to 50 at upstream $\left(45^{\circ}\right)$, broadside $\left(90^{\circ}\right)$, and downstream $\left(135^{\circ}\right)$ observers are presented in Figure 7 Note that only even shaft orders are presented as there are an even number of blades in the forward and aft blade rows. Conclusions consistent with those from the directivity plots may be drawn for the individual rotor tones. The low order interaction tones $\left(\mathrm{BPF}_{1}+\mathrm{BPF}_{2}, \mathrm{BPF}_{1}+2 \mathrm{BPF}_{2}, 2 \mathrm{BPF}_{1}+\mathrm{BPF}_{2}\right)$ corresponding to shaft orders 22,32 , and 34 are fairly well captured with some over-prediction at select observer angles. The higher order interaction tones $\left(\mathrm{BPF}_{1}+3 \mathrm{BPF}_{2}, 2 \mathrm{BPF}_{1}+2 \mathrm{BPF}_{2}, 3 \mathrm{BPF}_{1}+\mathrm{BPF}_{2}\right)$ corresponding to shaft orders 42,44 , and 46 are also captured fairly well. However, there appears to be under-prediction of the measured levels as the shaft order increases. A similar effect appears to occur with the higher harmonics of the individual rotor tones (i.e., $n \mathrm{BPF}_{1}$ and $n \mathrm{BPF}_{2}$ ). While they are captured, there is a generally consistent under-prediction over the various observer angles. As the higher order interaction tones and higher harmonics of the individual rotor tones are driven by the harmonics of the unsteady blade loading, these comparisons would likely improve with increased spatial grid resolution.

In addition to spatial grid resolution mentioned above, as discussed by Envia, ${ }^{6}$ a portion of the discrepancies noted above may also be due in part to blade-to-blade variations within the test hardware. The experimental data shows tones at all (both odd and even) shaft orders. However, since the blade counts are even, the predictions contain only even order tones (whether sum or difference). The predictions assume identical ('constant') blade shapes. In contrast, the actual test hardware likely includes some blade-to-blade shape and angle setting variation. Therefore, the precise phasing contained in the predictions does not occur and acoustic energy may be distributed across all shaft orders.

As shown in Figures 8 and 9 similar observations may be made for the 5551 RPM case. Directivity plots show individual rotor tones are well captured and the measured data trends appear to be well predicted. Comparison of tonal SPL also show similar trends over the various observer locations. Results of extracted levels for the 4620 RPM case are similar and therefore are not included. However, to provide further insight, Figure 10 shows comparisons of the overall sound pressure level (OASPL) in the shaft order range from 8 to 100 for all three rotor speeds. It should also be noted that since the measured levels include both tone and broadband content, it is necessary to subtract the broadband levels from the measured data before calculating the OASPL. Thus, the presented measured levels are based on the tone levels obtained from the aforementioned tonal extraction technique (Section III). As seen in previous comparisons, the measured data trends are captured reasonably well for the two higher rotor speeds. The two predictions follow very similar trends over these two speeds as well. However, at the lowest RPM case, the comparisons deteriorate, particularly at the upstream observer angles. It is interesting to note that at this rotor speed, the first interaction tone $\left(\mathrm{BPF}_{1}+\mathrm{BPF}_{2}\right)$ is a strong contributor to the OASPL at forward observer angles. As this is a tone for which comparisons between measurement and prediction were least favorable, this may be a possible cause for the larger discrepancy. Overall, the predicted OASPL levels generally decrease with decreasing rotor speed as seen in the measured levels. However, the rate at which the measured levels decrease does not match the measured values, particularly at the upstream observer angles. 


\section{B. Temporal Resolution Refinement}

Previous discussions pointed to the need for a temporal and spatial grid refinement study. While a full study is not included in this work, an initial OVERFLOW 2 temporal resolution study was undertaken to begin the investigation. This entailed performing additional aerodynamic predictions for the 6436 RPM case using temporal resolutions corresponding to azimuthal angles of $0.5^{\circ}$ and $0.25^{\circ}$. Acoustic predictions using these extracted blade surface pressures were then performed following the same approach as described above. Directivity plots corresponding to these predictions are presented in Figure 11. Here, the measured and baseline $1.0^{\circ}$ resolution results are again plotted for comparison with the higher temporal resolution results. In general, the increased temporal resolution does not appear to have a large effect on the predicted results. The trends in the predicted values are maintained and large deviations in absolute levels are generally not apparent. One exception is the first low order interaction tone $\left(\mathrm{BPF}_{1}+\mathrm{BPF}_{2}\right)$, for which a large deviation is evident at several downstream observer angles. This may, in part, be the result of the observer angle resolution, as the feature may appear at lower temporal resolutions at slightly different observers angles. However, as the overall directivity of this tone is not well captured, it may also be evidence of the need for increased spatial resolution. Further tone level and OASPL comparisons are presented in Figures 12 and 13 , respectively. Again, similar trends to those found in previous comparisons are observed. Thus, as might be expected from the performance parameter comparisons, the initial temporal grid refinement did not yield major changes in the general prediction quality. However, since the initial temporal resolution was likely acceptable for the frequencies considered, future work on spatial grid refinement may yield more significant modification to the predictions.

\section{Concluding Remarks}

In this study, the OVERFLOW 2 and FUN3D codes were used to predict the aerodynamic performance of the baseline F31A31 blade set. Blade surface pressure results from the aerodynamic predictions were then used with PSU-WOPWOP and the F1A module of NASA's second generation Aircraft NOise Prediction Program to predict the open rotor noise source. Although prediction of absolute levels may be difficult, comparisons between measurement and predictions indicate that general trends were captured fairly well. Evidence of the need for increased spatial grid resolution was observed and a more complete grid refinement study will be pursued in future work. Overall, the results indicate that the computational approach is acceptable for assessing low-noise rotor designs. Additionally, this approach may be used to provide realistic incident source fields for acoustic shielding/scattering studies on various aircraft configurations.

\section{Acknowledgments}

This research was funded by the Advanced Air Transport Technology Project of NASA's Advanced Air Vehicles Program.

\section{References}

\footnotetext{
${ }^{1}$ Hager, R. D. and Vrabel, D., “Advanced Turboprop Project,” NASA SP 495, 1988.

${ }^{2}$ Nichols, H. E., "UDF ${ }^{\circledR}$ Engine/MD-80 Flight Test Program,” AIAA Paper 88-2805, 1988.

${ }^{3}$ Zante, D. E. V., Gazzaniga, J. A., Elliott, D. M., and Woodward, R. P., "An Open Rotor Test Case: F31/A31 Historical Baseline Blade Set," ISABE 2011-1310, 2011.

${ }^{4}$ Stephens, D. B., "Data Summary Report for the Open Rotor Propulsion Rig Equipped with F31/A31 Rotor Blades," NASA TM 2014-216676, 2014.

${ }^{5}$ Sree, D., "Far-Field Acoustic Power Level and Performance Analyses of F31/A31 Open Rotor Model at Simulated Scaled Takeoff, Nominal Takeoff, and Approach Conditions: Technical Report I," NASA CR 2015-218716, 2015.

${ }^{6}$ Envia, E., "Open Rotor Aeroacoustic Modeling," NASA TM 2012-217740, 2012.

${ }^{7}$ Rizzi, S. A., Stephens, D. B., Berton, J. J., Zante, D. E. V., Wojno, J. P., and Goerig, T. W., "Auralization of Flyover Noise from Open Rotor Engines Using Model Scale Test Data," AIAA Paper 2014-2750, 2014.

${ }^{8}$ Nichols, R. H. and Buning, P. G., "User's Manual for OVERFLOW 2.2," http://overflow.larc.nasa.gov/home/users-manual-for-overflow-2-2/, (Version 2.2k, March 2015).

${ }^{9}$ Nichols, R. H., Tramel, R. W., and Buning, P. G., "Solver and Turbulence Model Upgrades to OVERFLOW2 for Unsteady and High-Speed Applications," AIAA Paper 2006-2824, 2006.

${ }^{10}$ Buning, P. G., "CFD Approaches for Simulation of Wing-Body Stage Separation," AIAA Paper 2004-4838.

${ }^{11}$ Boyd, D. D., "HART-II Acoustic Predictions using a Coupled CFD / CSD Method," American Helicopter Society 65th Annual Forum, Grapevine, TX, 2009.
} 
${ }^{12}$ Steger, J. L., Dougherty, F. C., and Benek, J. A., "A Chimera Grid Scheme," Advances in Grid Generation, edited by K. N. Ghia and U. Ghia, ASME FED-Vol. 5, June 1983.

${ }^{13}$ Chan, W. M., III, R. J. G., Rogers, S. E., and Buning, P. G., "Best Practices in Overset Grid Generation,” AIAA Paper 2002-3191, 2002.

14“FUN3D User Manual," http://fun3d.larc.nasa.gov.

${ }^{15}$ Anderson, W. K. and Bonhaus, D. L., "An Implicit Upwind Algorithm for Computing Turbulent Flows on Unstructured Grids," Computers and Fluids, Vol. 23, No. 1, 1994, pp. 1-21.

${ }^{16}$ Anderson, W. K., Rausch, R. D., and Bonhaus, D. L., "Implicit/Multigrid Algorithms for Incompressible Turbulent Flows on Unstructured Grids," Journal of Computational Physics, Vol. 128, No. 2, 1996, pp. 391-408.

${ }^{17}$ Nielsen, E. J., Aerodynamic Design Sensitivities on an Unstructured Mesh Using the Navier-Stokes Equations and a Discrete Adjoint Formulation, Ph.D. thesis, Virginia Polytechnic Institute and State University, Department of Aerospace and Ocean Engineering, December 1998.

${ }^{18}$ Biedron, R. T. and Thomas, J. L., "Recent Enhancements to the FUN3D Flow Solver for Moving-Mesh Applications," AIAA Paper 20091360, 2009.

${ }^{19}$ Roe, P. L., "Approximate Riemann Solvers, Parameter Vectors, and Difference Schemes," Journal of Computational Physics, Vol. 43, No. 2, 1981, pp. 357-372.

${ }^{20}$ Spalart, P. R. and Allmaras, S. R., “A One-Equation Turbulence Model for Aerodynamic Flows,” AIAA Paper 92-0439, 1992.

${ }^{21}$ Dacles-Mariani, J., Zilliac, G., Chow, J. S., and Bradshaw, P., "Numerical/Experimental Study of a Wingtip Vortex in the Near Field," AIAA Journal, Vol. 33, No. 9, 1995, pp. 1561-1568.

${ }^{22}$ Vatsa, V., Carpenter, M., and Lockard, D., "Re-evaluation of an Optimized Second Order Backward Difference (BDF2OPT) Scheme for Unsteady Flow Applications," AIAA Paper 2010-0122, 2010.

${ }^{23}$ Jones, W. T., "GridEx - An Integrated Grid Generation Package for CFD," AIAA Paper 2003-4129, 2003.

${ }^{24}$ Haimes, R., CAPRI: Computational Analysis PRogramming Interface User's Guide, Massachusetts Institute of Technology, 2001.

${ }^{25}$ Parikh, P., Pirzadeh, S., and Löhner, R., "A Package for 3-D Unstructured Grid Generation,” Tech. rep., Finite Element Flow Solution and Flow Field Visualization.

${ }^{26}$ Marcum, D. L., "Generation of Unstructured Grids for Viscous Flow Applications," AIAA Paper 95-0212, 1995.

${ }^{27}$ Noack, R., Boger, D., Kunz, R., and Carrica, P., "SUGGAR++: An Improved General Overset Grid Assembly Capability," AIAA Paper 2009-3992, 2009.

${ }^{28}$ Williams, J. E. F. and Hawkings, D. L., "Sound Generation by Turbulence and Surfaces in Arbitrary Motion," Philosophical Transactions of the Royal Society of London A, Vol. 342, 1969, pp. 264-321.

${ }^{29}$ Brentner, K. S., Lopes, L. V., Chen, H. N., and Horn, J. F., "Near Real-Time Simulation of Rotorcraft Acoustics and Flight Dynamics," AIAA Journal, Vol. 42, No. 2, March-April 2005, pp. 347-355.

${ }^{30}$ Lopes, L. V. and Burley, C. L., "Design of the Next Generation Aircraft NOise Prediction Program: ANOPP2," AIAA Paper 2011-2854, 2011. 


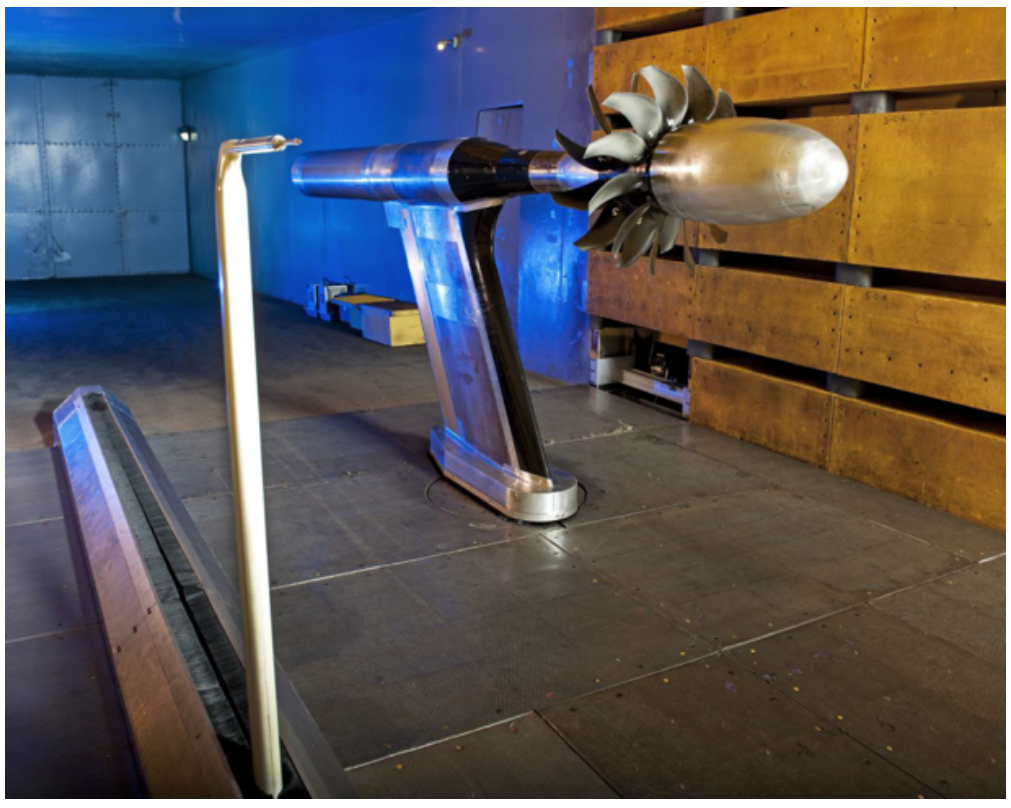

Figure 1: F31A31 test hardware installed in the NASA 9-ft. x 15-ft. wind tunnel.

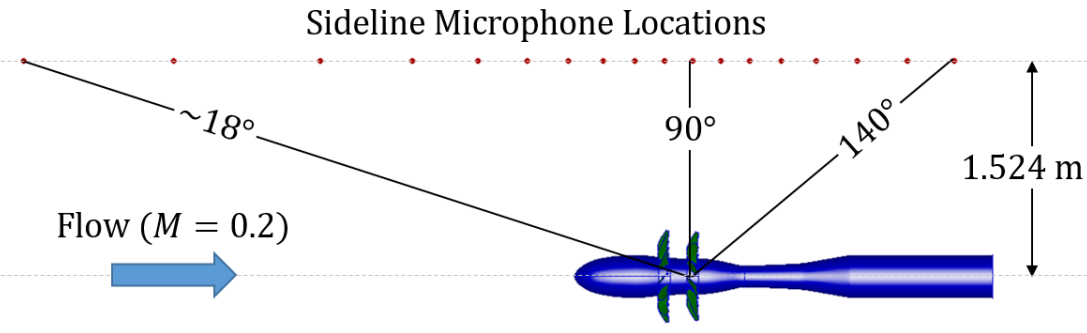

Figure 2: F31A31 test hardware installed in the NASA 9-ft. x 15-ft. wind tunnel.

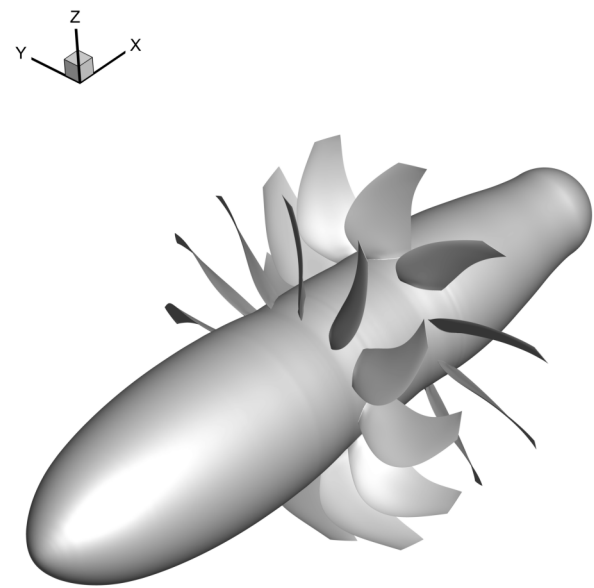

(a) OVERFLOW 2.

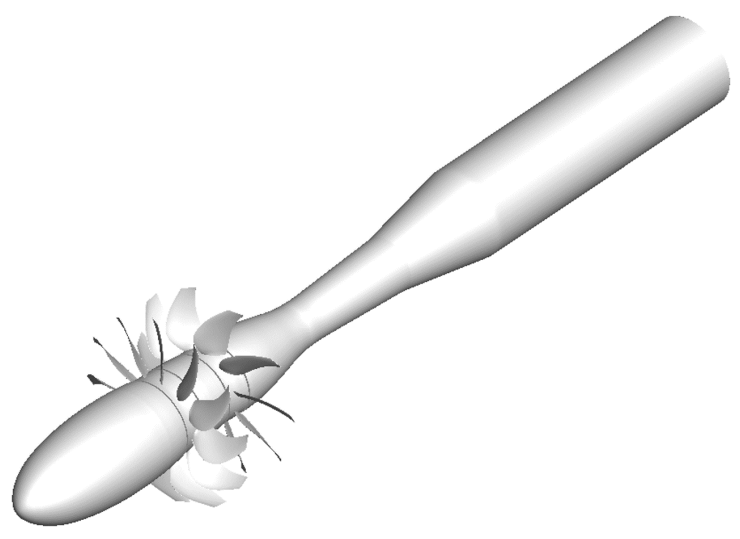

(b) FUN3D.

Figure 3: Computational surfaces for aerodynamic calculations. 


\begin{tabular}{|c|c|c|c|}
\hline Observer Angle [deg] & $\mathrm{x}[\mathrm{m}]$ & $\mathrm{y}[\mathrm{m}]$ & $\mathrm{z}[\mathrm{m}]$ \\
\hline \hline 17.8 & -3.907 & 1.524 & 0.0 \\
\hline 22.5 & -2.840 & 1.524 & 0.0 \\
\hline 30.0 & -1.800 & 1.524 & 0.0 \\
\hline 37.5 & -1.146 & 1.524 & 0.0 \\
\hline 45.0 & -0.684 & 1.524 & 0.0 \\
\hline 52.5 & -0.330 & 1.524 & 0.0 \\
\hline 60.0 & -0.040 & 1.524 & 0.0 \\
\hline 67.7 & 0.208 & 1.524 & 0.0 \\
\hline 75.0 & 0.431 & 1.524 & 0.0 \\
\hline 82.5 & 0.639 & 1.524 & 0.0 \\
\hline 90.0 & 0.840 & 1.524 & 0.0 \\
\hline 97.5 & 1.040 & 1.524 & 0.0 \\
\hline 105.0 & 1.248 & 1.524 & 0.0 \\
\hline 112.5 & 1.471 & 1.524 & 0.0 \\
\hline 120.0 & 1.720 & 1.524 & 0.0 \\
\hline 127.5 & 2.009 & 1.524 & 0.0 \\
\hline 135.0 & 2.364 & 1.524 & 0.0 \\
\hline 140.6 & 2.695 & 1.524 & 0.0 \\
\hline & & & \\
\hline
\end{tabular}

Table 1: Sideline microphone locations in the 9-ft. x15-ft. wind tunnel.

\begin{tabular}{|c|c|c|c|c|c|c|}
\hline \multirow{2}{*}{ Case } & \multicolumn{3}{|c|}{ Front Rotor } & \multicolumn{2}{c|}{ Aft Rotor } & \\
\cline { 2 - 7 } & Number of Blades & Blade Angle & RPM & Number of Blades & Blade Angle & RPM \\
\hline \hline 1 & 12 & $40.1^{\circ}$ & 4620 & 10 & $40.8^{\circ}$ & 4620 \\
\hline 2 & 12 & $40.1^{\circ}$ & 5551 & 10 & $40.8^{\circ}$ & 5551 \\
\hline 3 & 12 & $40.1^{\circ}$ & 6436 & 10 & $40.8^{\circ}$ & 6436 \\
\hline
\end{tabular}

Table 2: Rotor parameters and flight conditions considered.

\begin{tabular}{|c|c|c|c|c|}
\hline \multirow{2}{*}{ Temporal Resolution [deg.] } & \multicolumn{2}{|c|}{ Thrust [N] } & \multicolumn{2}{c|}{ Torque [Nm] } \\
\cline { 2 - 5 } & Rotor 1 & Rotor 2 & Rotor 1 & Rotor 2 \\
\hline \hline 1.00 & 1383.7 & 1401.0 & 262.8 & 247.8 \\
\hline 0.50 & 1378.2 & 1403.2 & 261.8 & 248.2 \\
\hline 0.25 & 1379.5 & 1400.5 & 262.8 & 248.9 \\
\hline
\end{tabular}

Table 3: Predicted OVERFLOW 2 performance parameters for various temporal resolutions $\left(\mathrm{RPM}_{1}=\mathrm{RPM}_{2}=6436\right)$. 


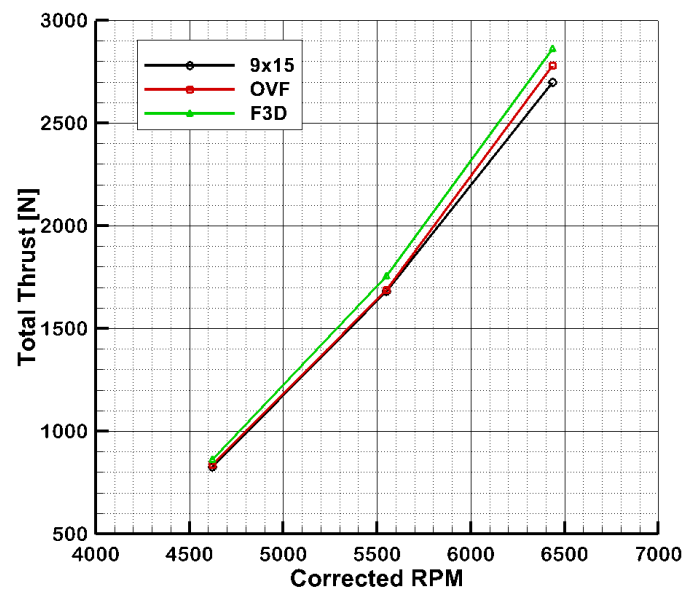

(a) Total thrust produced by both rotors.

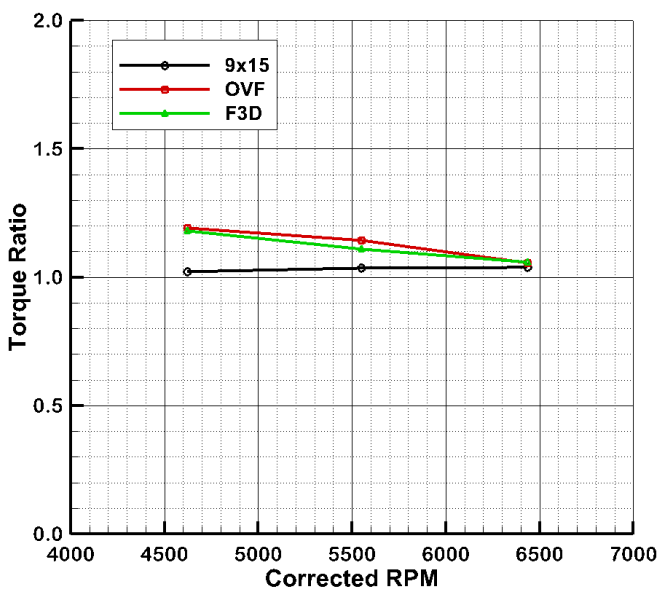

(b) Torque ratio.

Figure 4: Measured (9x15) and predicted F31A31 performance parameters as a function of RPM $(M=0.2)$. Predicted values are based on OVERFLOW2 (OVF) and FUN3D( F3D) loading obtained at a temporal resolution corresponding to a 1.0 degree azimuthal angle.

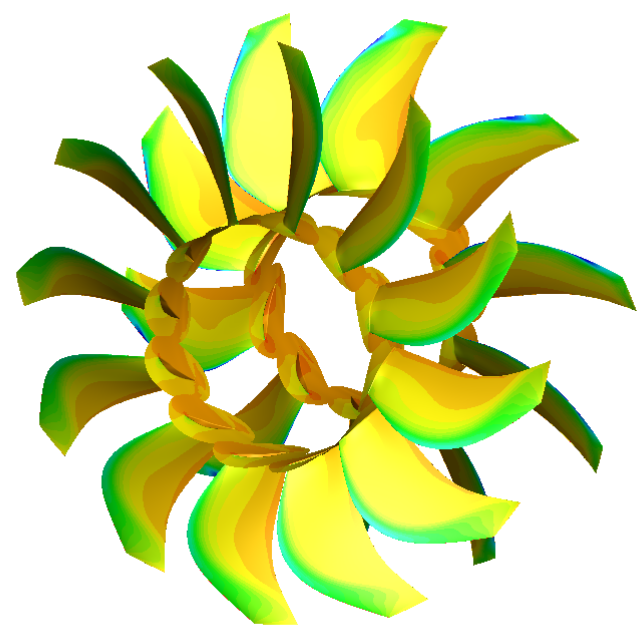

(a) Overflow2.

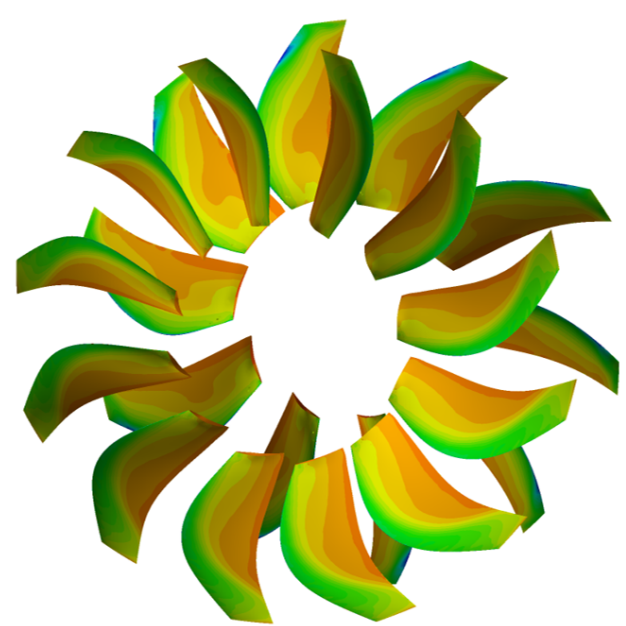

(b) FUN3D.

Figure 5: Impermeable data surfaces used in acoustic predictions. 


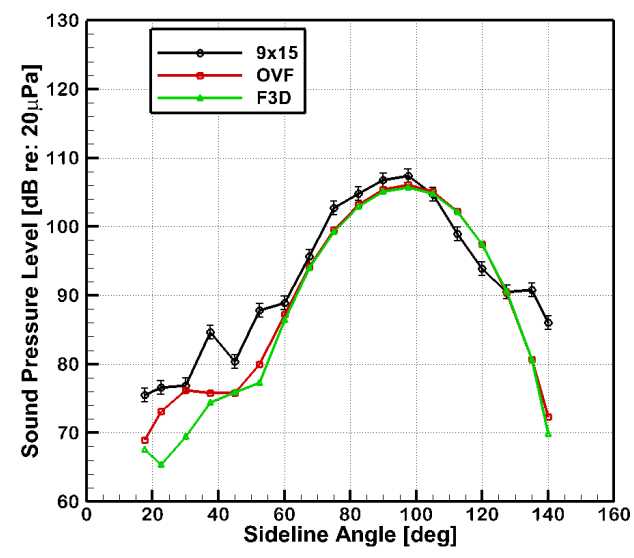

(a) $\mathrm{BPF}_{2}$ : Shaft Order $=10$

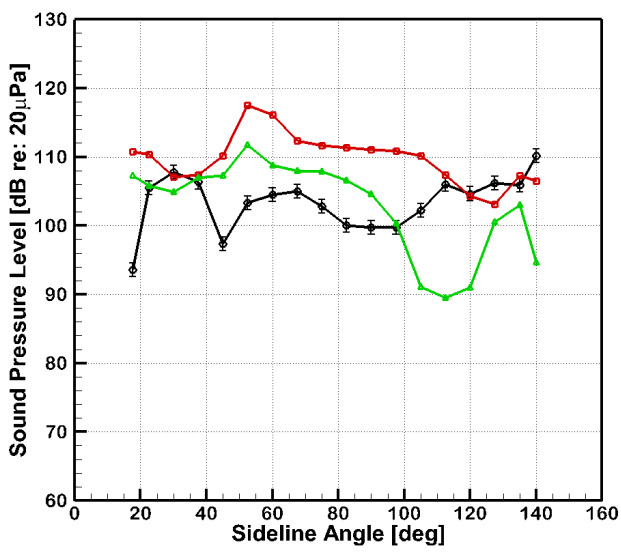

(c) $\mathrm{BPF}_{1}+\mathrm{BPF}_{2}:$ Shaft Order $=22$.

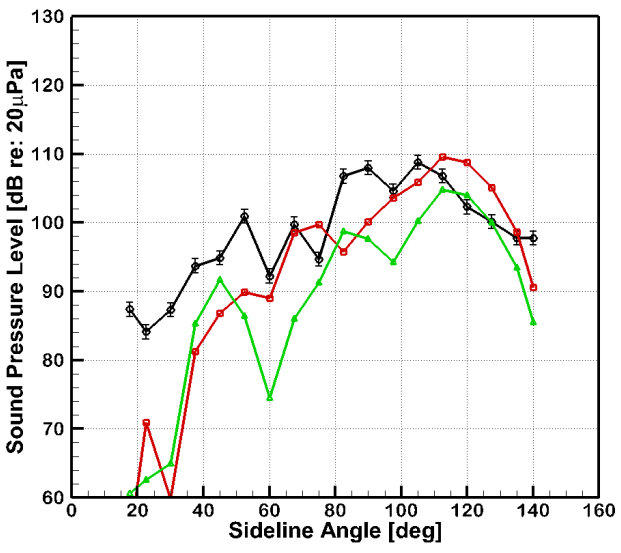

(e) $2 \mathrm{BPF}_{1}+\mathrm{BPF}_{2}:$ Shaft Order $=34$.

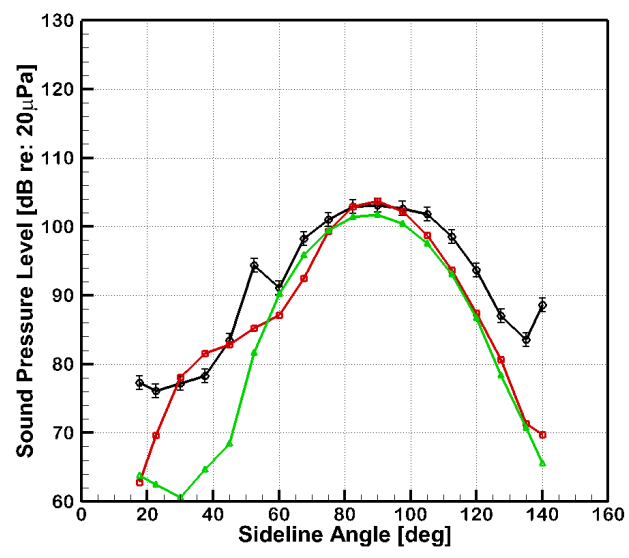

(b) $\mathrm{BPF}_{1}$ : Shaft Order $=12$.

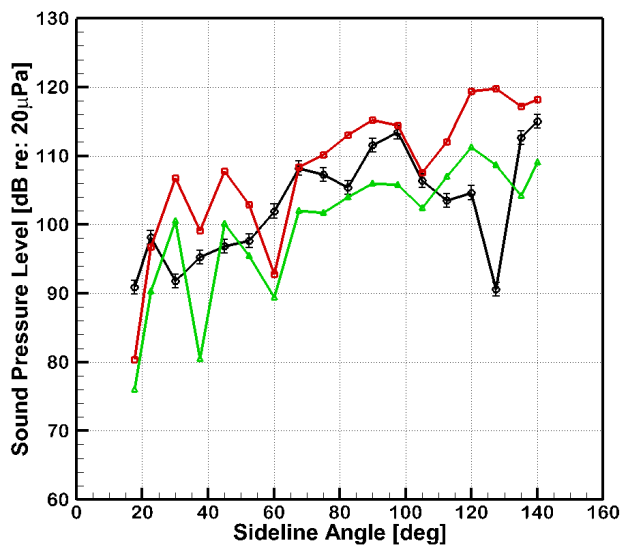

(d) $\mathrm{BPF}_{1}+2 \mathrm{BPF}_{2}:$ Shaft Order $=32$.

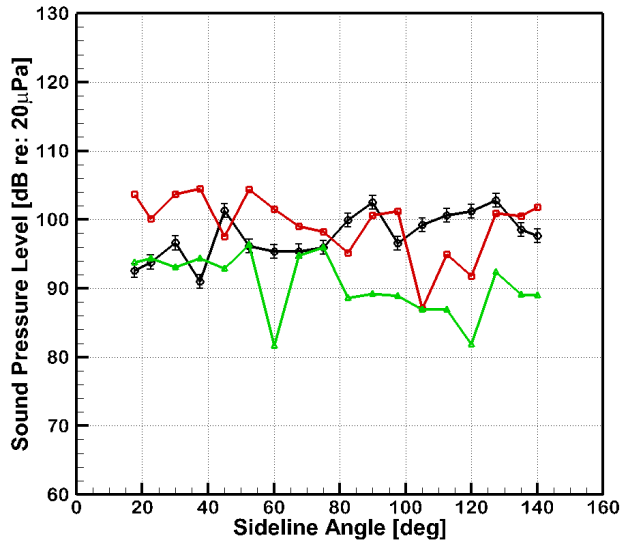

(f) $2 \mathrm{BPF}_{1}+2 \mathrm{BPF}_{2}:$ Shaft Order $=44$.

Figure 6: Comparison of measured $(9 \times 15)$ and predicted SPL levels as a function of sideline angle $\left(\mathrm{RPM}_{1}=\mathrm{RPM}_{2}=\right.$ $6436, M=0.2$ ). Predicted values are based on OVERFLOW2 (OVF) and FUN3D(F3D) loading obtained at a temporal resolution corresponding to a 1.0 degree azimuthal angle. 


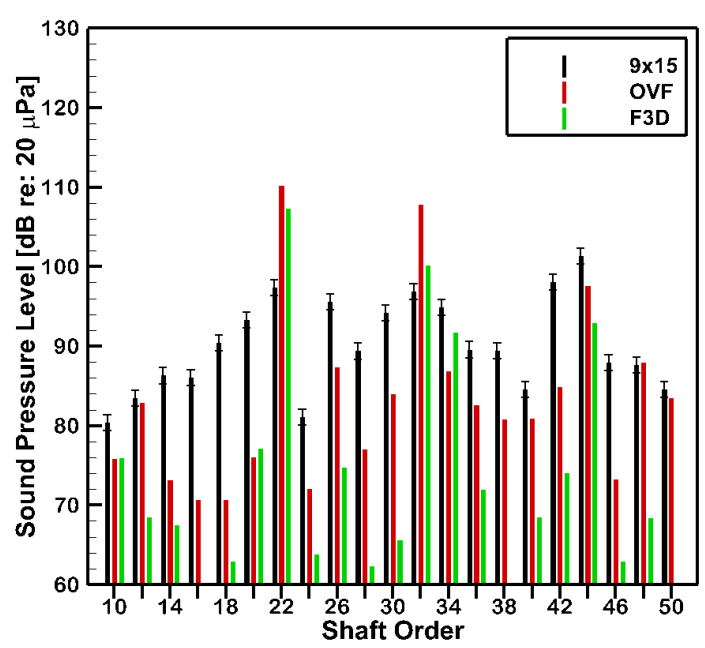

(a) 45 Deg.

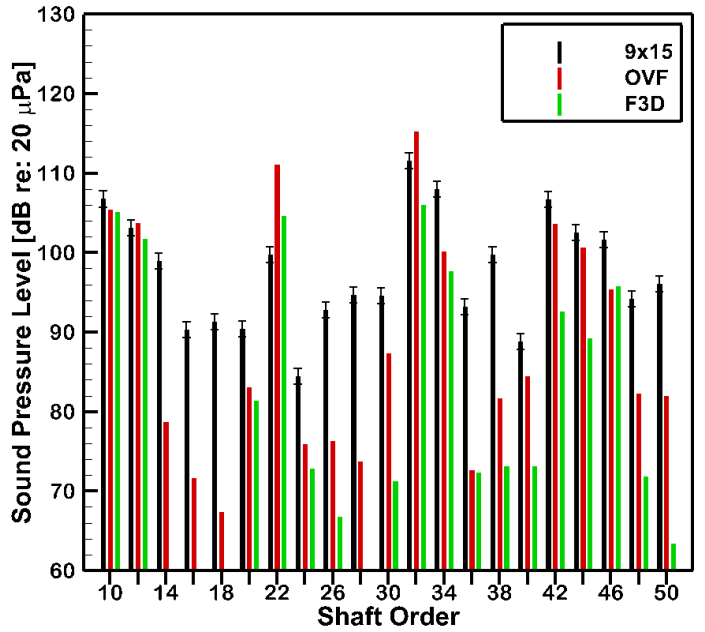

(b) 90 Deg.

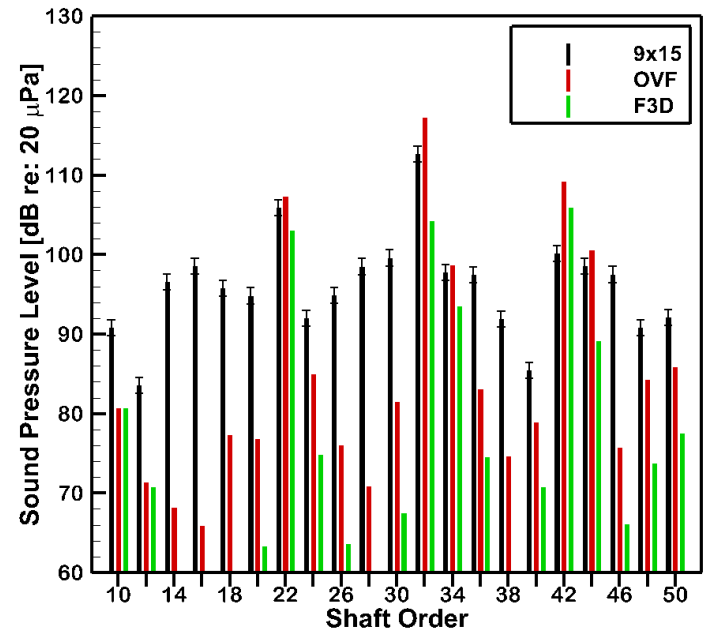

(c) 135 Deg.

Figure 7: Comparison of measured $(9 x 15)$ and predicted tone $S P L$ at various sideline observer angles $\left(\mathrm{RPM}_{1}=\mathrm{RPM}_{2}=\right.$ $6436, M=0.2$ ). Predicted values are based on OVERFLOW2 (OVF) and FUN3D(F3D) loading obtained at a temporal resolution corresponding to a 1.0 degree azimuthal angle. 


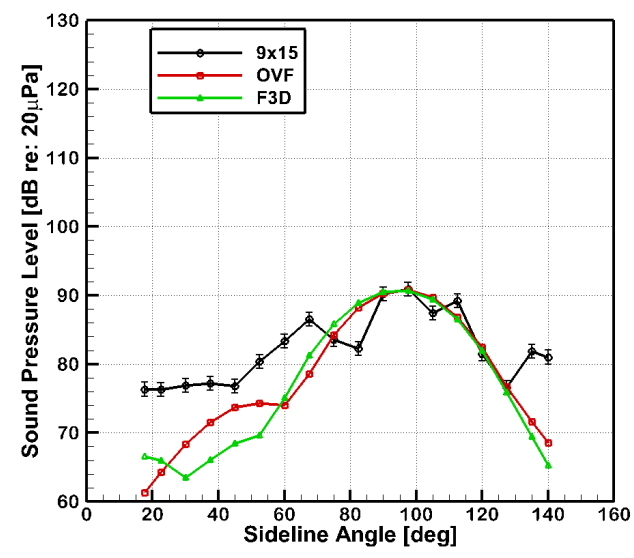

(a) $\mathrm{BPF}_{2}$ : Shaft Order $=10$

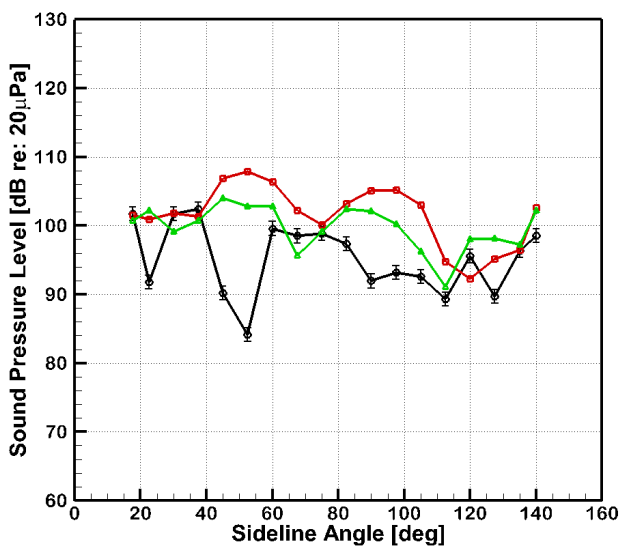

(c) $\mathrm{BPF}_{1}+\mathrm{BPF}_{2}:$ Shaft Order $=22$.

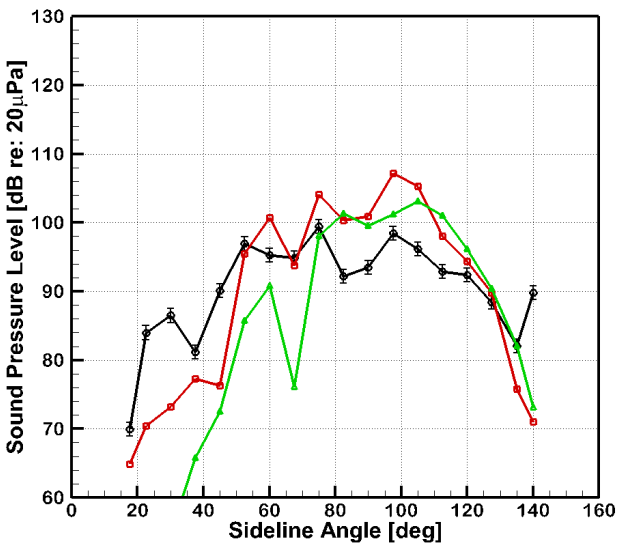

(e) $2 \mathrm{BPF}_{1}+\mathrm{BPF}_{2}$ : Shaft Order $=34$.

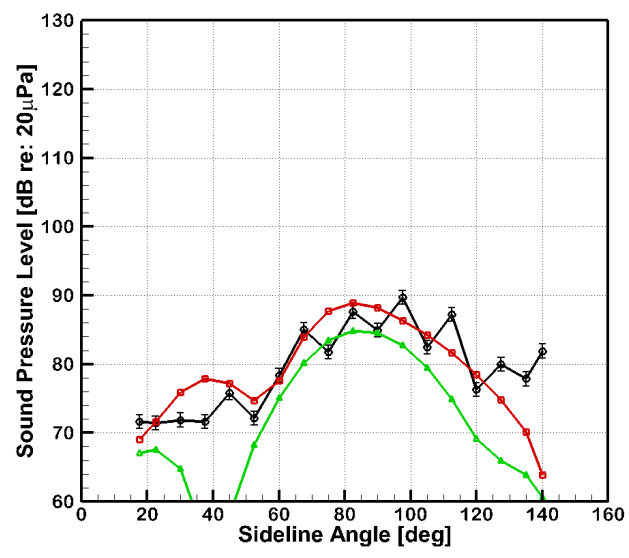

(b) $\mathrm{BPF}_{1}$ : Shaft Order $=12$.

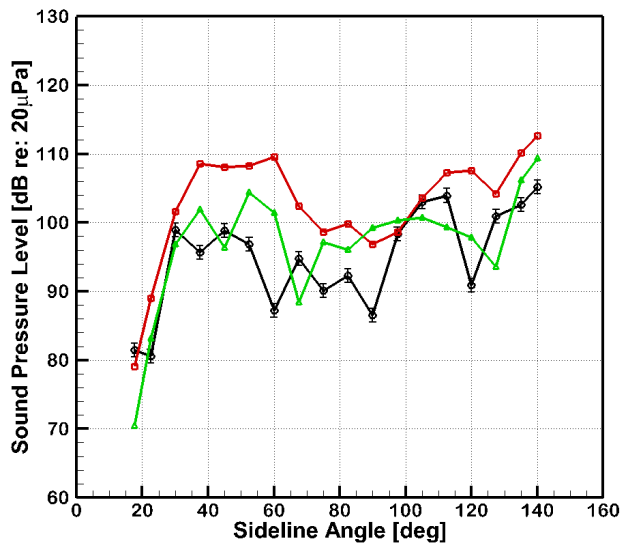

(d) $\mathrm{BPF}_{1}+2 \mathrm{BPF}_{2}:$ Shaft Order $=32$.

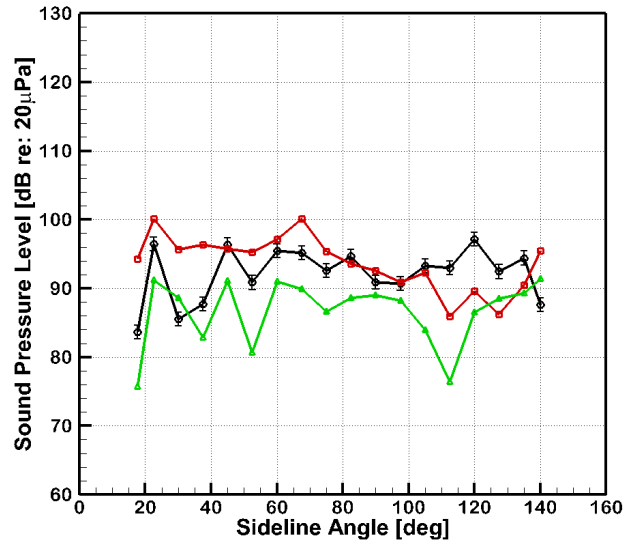

(f) $2 \mathrm{BPF}_{1}+2 \mathrm{BPF}_{2}$ : Shaft Order $=44$

Figure 8: Comparison of measured (9x15) and predicted SPL levels as function of sideline angle $\left(\mathrm{RPM}_{1}=\mathrm{RPM}_{2}=\right.$ 5551, $M=0.2$ ). Predicted values are based on OVERFLOW2 (OVF) and FUN3D (F3D) loading obtained at temporal resolutions corresponding to a 1.0 degree azimuthal angle. 


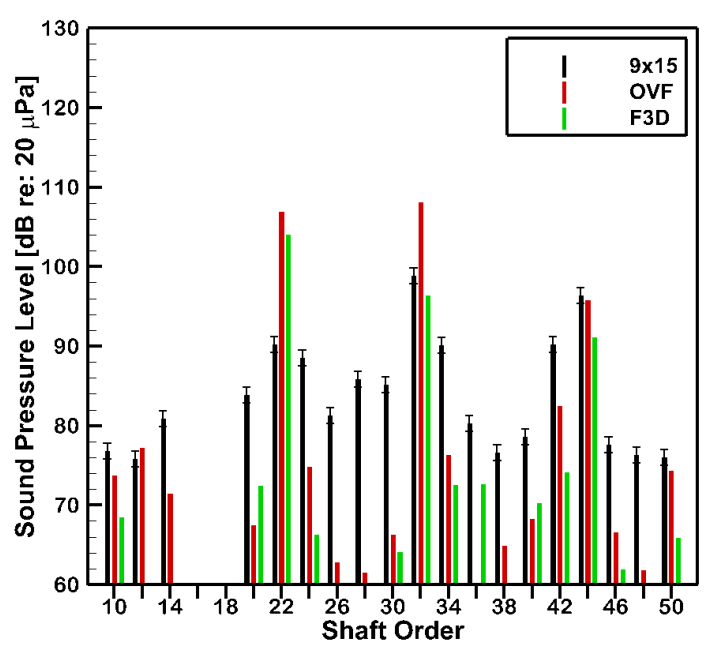

(a) 45 Deg.

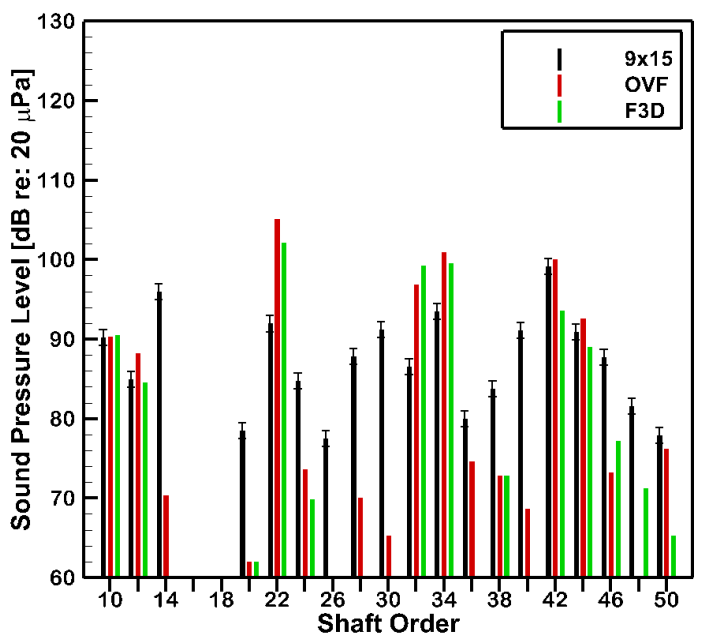

(b) 90 Deg.

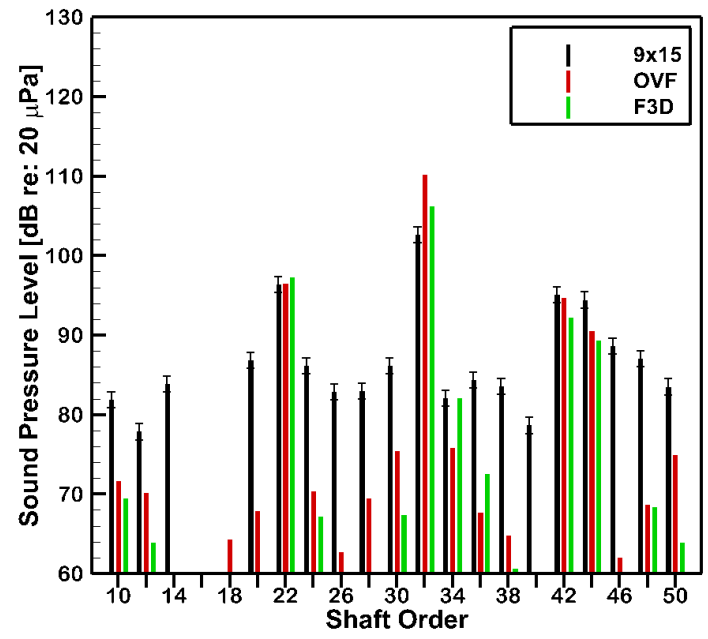

(c) 135 Deg.

Figure 9: Comparison of measured $(9 \times 15)$ and predicted tone $S P L$ at various sideline observer angles $\left(\mathrm{RPM}_{1}=\mathrm{RPM}_{2}=\right.$ $5551, M=0.2$ ). Predicted values are based on OVERFLOW2 (OVF) and FUN3D(F3D) loading obtained at a temporal resolution corresponding to a 1.0 degree azimuthal angle. 


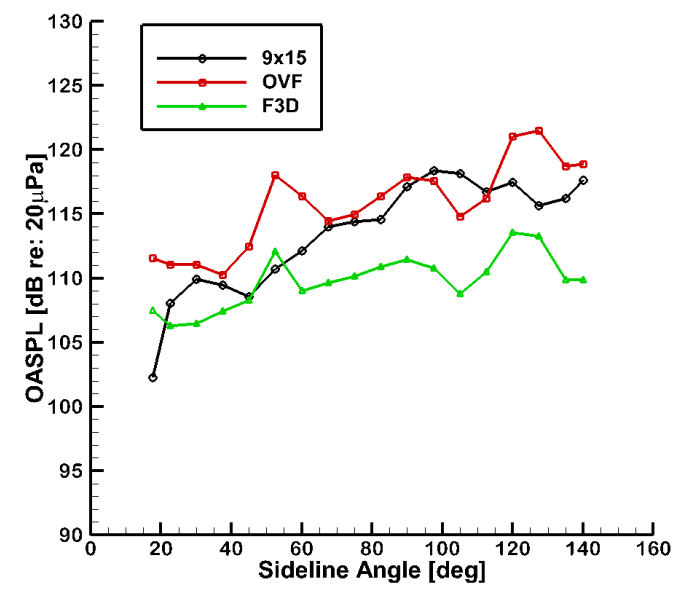

(a) $\mathrm{RPM}_{1}=\mathrm{RPM}_{2}=6436$

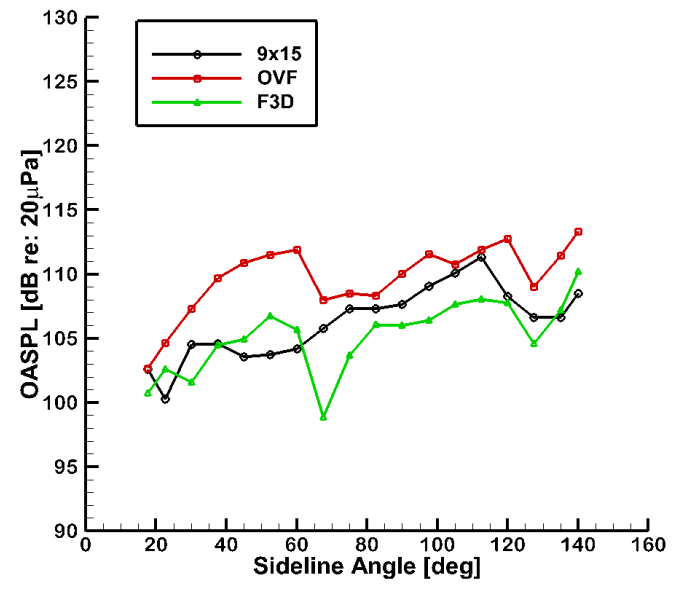

(b) $\mathrm{RPM}_{1}=\mathrm{RPM}_{2}=5551$

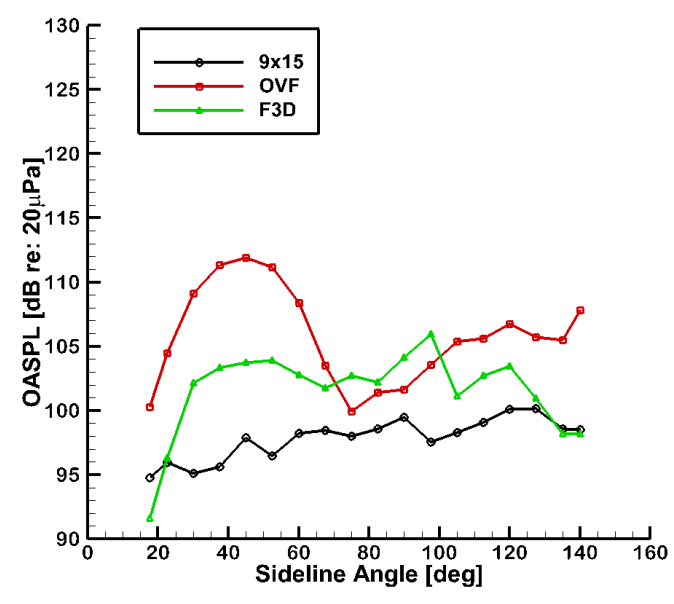

(c) $\mathrm{RPM}_{1}=\mathrm{RPM}_{2}=4620$

Figure 10: Comparison of measured (Experiment) and predicted OASPL levels as a function of sideline angle $\left(\mathrm{RPM}_{1}=\right.$ $\mathrm{RPM}_{2}=6436, M=0.2$ ). Predicted values are based on OVERFLOW2 (OVF) and FUN3D( F3D) loading obtained at a temporal resolution corresponding to a 1.0 degree azimuthal angle. 


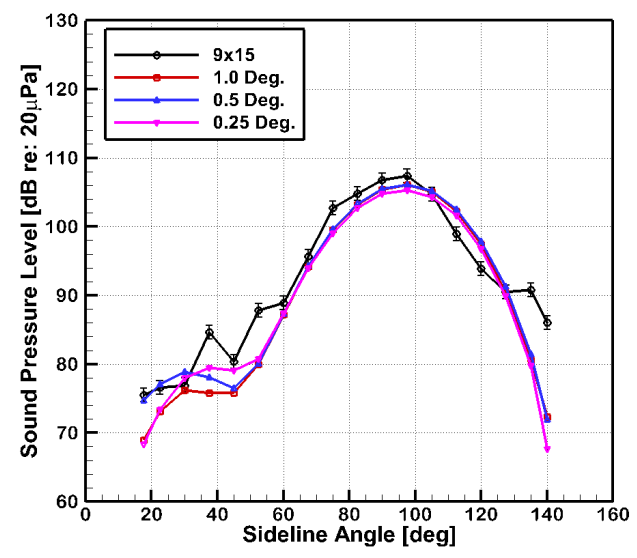

(a) $\mathrm{BPF}_{2}$ : Shaft Order $=10$.

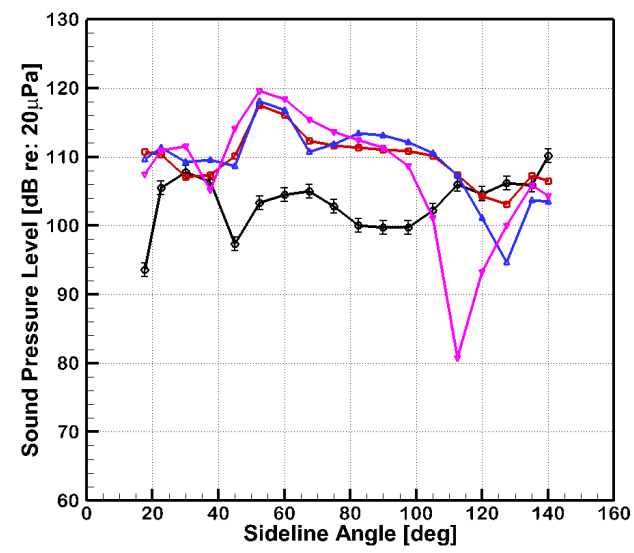

(c) $\mathrm{BPF}_{1}+\mathrm{BPF}_{2}:$ Shaft Order $=22$.

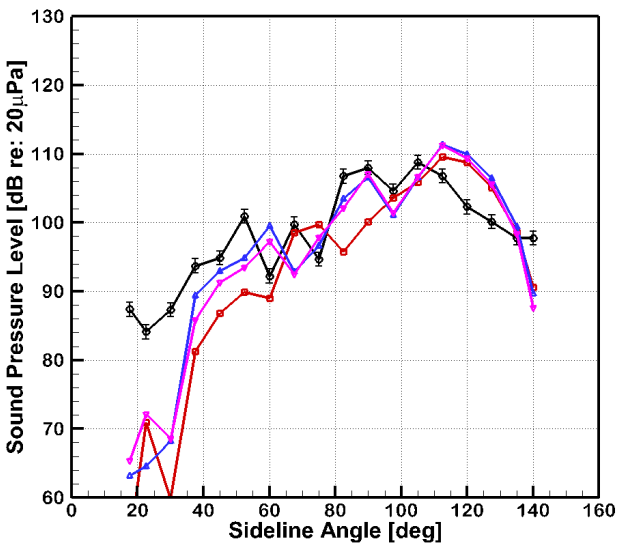

(e) $2 \mathrm{BPF}_{1}+\mathrm{BPF}_{2}$ : Shaft Order $=34$.

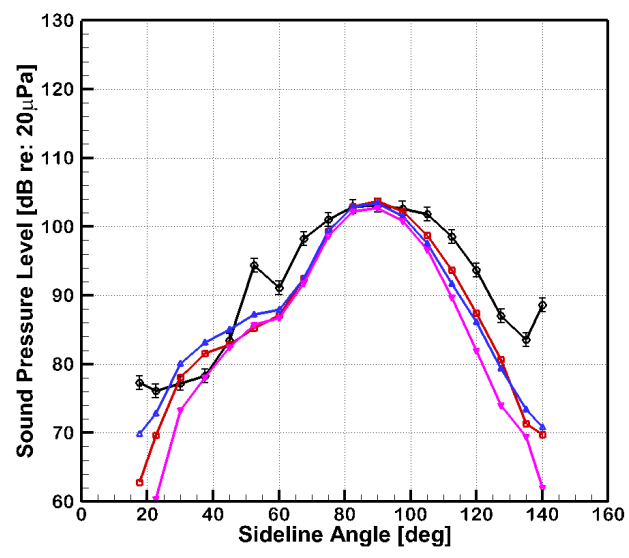

(b) $\mathrm{BPF}_{2}$ : Shaft Order $=12$.

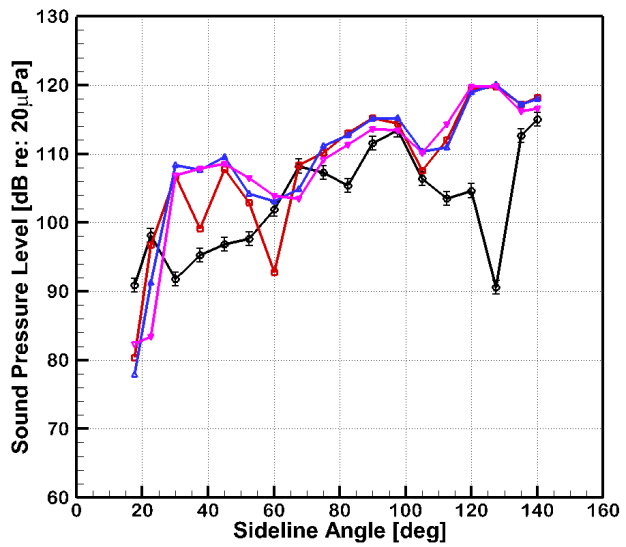

(d) $\mathrm{BPF}_{1}+2 \mathrm{BPF}_{2}:$ Shaft Order $=32$.

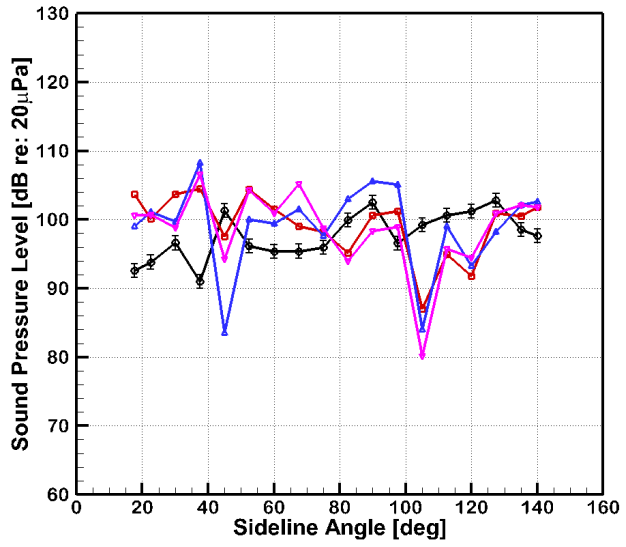

(f) $2 \mathrm{BPF}_{1}+2 \mathrm{BPF}_{2}:$ Shaft Order $=44$.

Figure 11: Comparison of measured $(9 \mathrm{x} 15)$ and predicted SPL for various interaction tones as a function of sideline angle $\left(\mathrm{RPM}_{1}=\mathrm{RPM}_{2}=6436, M=0.2\right)$. Predicted values are based on OVERFLOW2 loading obtained at temporal resolutions corresponding to $1.0,0.5$, and 0.25 degree azimuthal angles. 


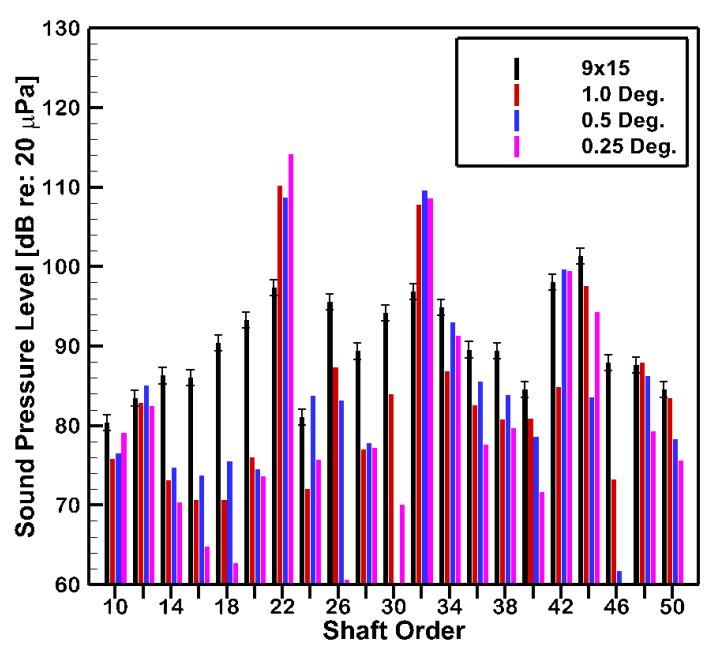

(a) Sideline Angle $=45^{\circ}$

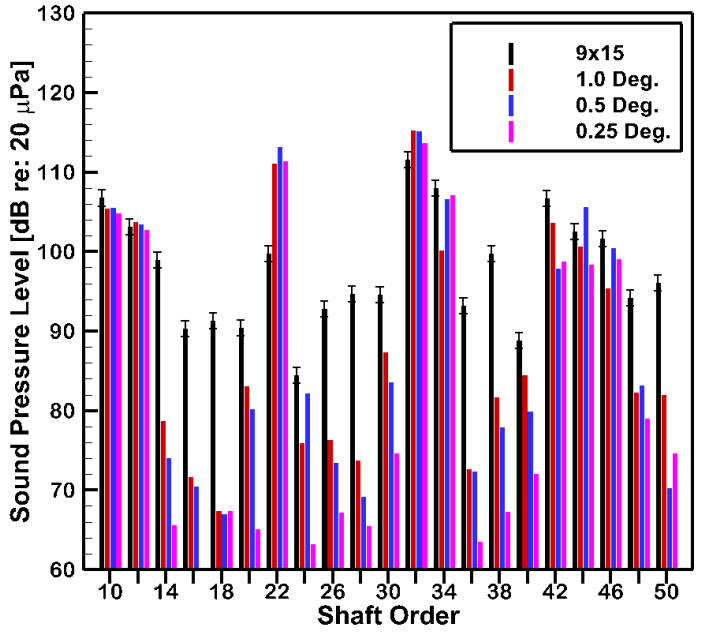

(b) Sideline Angle $=90^{\circ}$

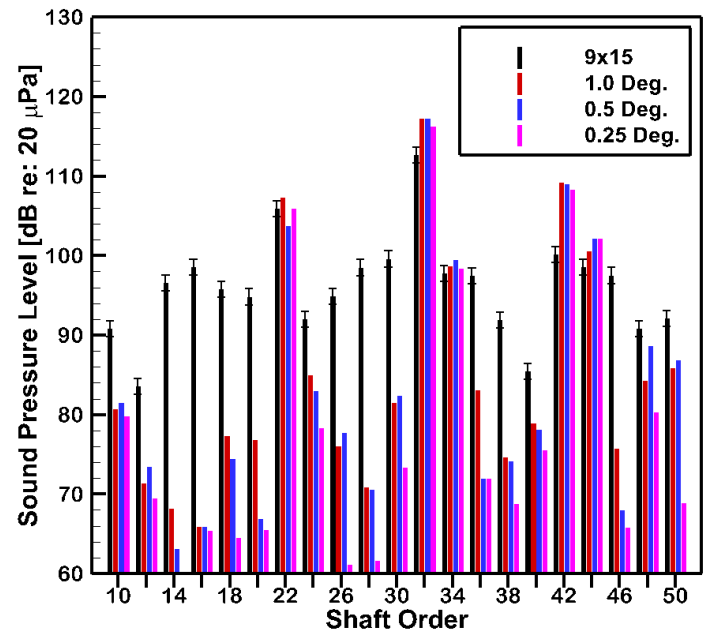

(c) Sideline Angle $=135^{\circ}$

Figure 12: Comparison of measured $(9 \mathrm{x} 15)$ and predicted tone SPL at various sideline observer angles $\left(\mathrm{RPM}_{1}=\right.$ $\mathrm{RPM}_{2}=6436, M=0.2$ ). Predicted values are based on OVERFLOW2 loading obtained at temporal resolutions corresponding to $1.0,0.5$, and 0.25 degree azimuthal angles. 


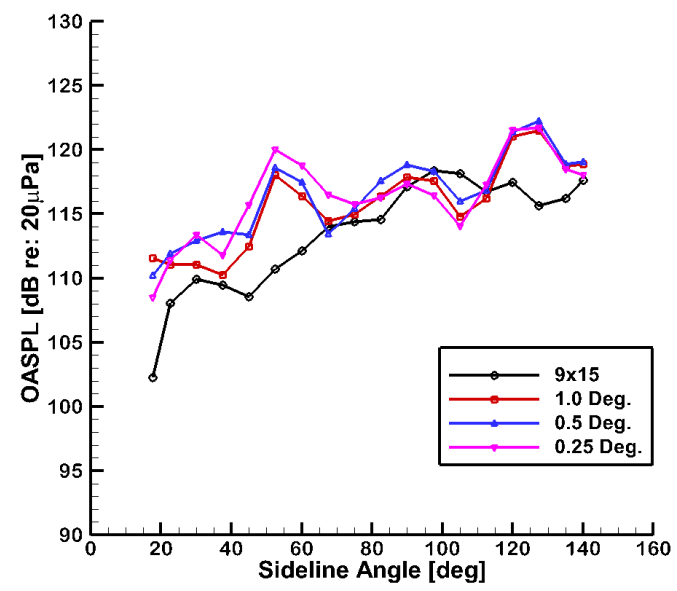

Figure 13: Comparison of measured (9x15) and predicted OASPL levels as a function of sideline angle $\left(\mathrm{RPM}_{1}=\right.$ $\left.\mathrm{RPM}_{2}=6436, M=0.2\right)$. Predicted values are based on OVERFLOW2 loading obtained at temporal resolutions corresponding to $1.0,0.5$, and 0.25 degree azimuthal angles. 